\title{
A Study of the Effect of Citrus aurantium L. Essential Oil on Anxiety and Its Interaction with GABAergic Pathways in Male Mice
}

\author{
Maryam Khosravi ${ }^{1}$, Shahrzad Khakpour ${ }^{2}$, Leila Adibi ${ }^{1}$, Mahsa Hadipour Jahromy ${ }^{2 *}$ \\ ${ }^{1}$ Biology Department, Faculty of Biological Sciences, Islamic Azad University North Tehran Branch, Tehran, Iran \\ ${ }^{2}$ Faculty of Medicine, Medical Sciences Research Center, Tehran Medical Branch, Islamic Azad University, \\ Tehran, Iran \\ Email: jahromymh@yahoo.com
}

Received 17 August 2014; revised 2 October 2014; accepted 17 October 2014

Copyright (C) 2014 by authors and Scientific Research Publishing Inc.

This work is licensed under the Creative Commons Attribution International License (CC BY).

http://creativecommons.org/licenses/by/4.0/

c) (i) Open Access

\begin{abstract}
Anxiety is among the most common disorders affecting a great number of people. Different neurotransmitter systems, such as GABAergic system, play an important role in emergence of anxietyrelated behaviors. In this study, we have investigated the effect of Citrus aurantium L. essential oil on anxiety and its interaction with GABAergic pathways. Male mice were assigned into control, sham, and experimental groups. Intraperitoneal injection of Citrus aurantium L. essential oil was applied at doses of $0.5,2.5$, and 5 percent for 5 days. Diazepam $(0.1 \mathrm{mg} / \mathrm{kg})$ was injected on the fifth day, thirty minutes before applying Citrus aurantium L. essential oil. The anxiety-related behavior of mice was then assessed using elevated plus-maze test. In groups receiving Citrus aurantium L. essential oil at doses of 2.5 and 5 percent, the percent time spent in the open arms increased significantly $(P<0.001)$. The injection of diazepam alone or with Citrus aurantium L. essential oil resulted in increasing in the number of entries to the open arms and the percent time spent in the open arms $(P<\mathbf{0 . 0 0 1})$. The results of this study show that Citrus aurantium L. essential oil can reduce anxiety-related behaviors in male mice thah may act via GABAergic system.
\end{abstract}

\section{Keywords}

Anxiety, Mice, Citrus aurantium L., Diazepam

\section{Introduction}

Anxiety is among the most serious and most common disorders in life which, compare to depressive disorders,

"Corresponding author.

How to cite this paper: Khosravi, M., Khakpour, S., Adibi, L. and Jahromy, M.H. (2014) A Study of the Effect of Citrus aurantium L. Essential Oil on Anxiety and Its Interaction with GABAergic Pathways in Male Mice. Journal of Behavioral and Brain Science, 4, 470-476. http://dx.doi.org/10.4236/jbbs.2014.410046 
has been given less serious attention. Anxiety disorders are often affiliated with medical chronic and age-related conditions such as asthma, thyroid disease, coronary artery disease, and dementia [1].

Today, anxiety is known as one of the major illnesses and dangers causing frailty in middle-aged people. Anxiety, on an elementary level, is nothing but a series of biochemical actions or changes in body and brain, such as the increase of adrenaline (which causes rapid heartbeat) or the reduction of dopamine (which helps soothing headache). These biochemical changes call for more attention for the source of anxiety. Too much anxiety prepares the body to either fight anxiety or escape from it; this is known as fight-or-flight response. Anxiety can appear in different forms. It is often accompanied by panic, fear, pain in the chest or stomach, shortage of breath, rapid heartbeat, or dizziness. It can also emerge in the form of uneasy and recurring thoughts or compulsory and uncontrollable behaviors [2].

GABA as an important inhibitory neurotransmitter system plays a significant role, whether directly or indirectly, in neurological disorders. Among disorders that are affiliated with $\mathrm{GABA}_{\mathrm{A}}$ receptor, we can name anxiety, cognitive impairment, hysteria, mental disorder, schizophrenia, and sleep disorder (insomnia). GABA is a neurotransmitter system which can reduce anxiety with an inhibitory effect. It has been observed that stress increases glutamate in prefrontal cortex and hippocampus [3]. In mice lacking GAD65 enzyme (that is, the enzyme that catalyzes the conversion of glutamate to GABA) anxiety-related behaviors have been observed. The level of GABA increases in pathogenesis of anxiety, depression, and insomnia. These symptoms develop as part of the main mental conditions in post-traumatic stress disorder (PSTD). A study on people suffering from PSTD shows that different beta-3 subunits of $\mathrm{GABA}_{\mathrm{A}}$ receptor are correlated with a high level of anxiety, insomnia, social disorder, and depression. There are many evidences on the changing of the GABA level in mental disorders [3].

Benzodiazepines are potent drugs that are generally prescribed as cure for anxiety, although they have minor side-effects as well [3]. Diazepam and other benzodiazepines impose their effects by acting on $\mathrm{GABA}_{\mathrm{A}}$ receptors at the binding site of gamma-2 subunit and alpha subunit, where the latter has a conserved histidineresidue in the second binding of benzodiazepine (N-Terminal extracellular). When diazepam, as a positive allosteric regulator of GABA (GABA agonist), is attached to benzodiazepine receptors, it produces inhibitory effects. This is the result of hyperpolarization of postsynaptic membrane which allows $\mathrm{CI}$ ions flow across through $\mathrm{GABA}_{\mathrm{A}}$ receptors. Benzodiazepines such as diazepam have no effect on the GABA levels in the brain. By influencing areas of limbic, thalamic and hypothalamic systems, diazepam produces anti-anxiety effects. Diazepam seeks to increase GABA activity. Benzodiazepine drugs such as diazepam increase the inhibitory effects in the cortex [4]. In mice that had mutation in the gene encoding $\alpha 1$ or $\alpha 2$ subunit, different responses to benzodiazepine have been observed. Mice that had mutation in gene encoding $\alpha 1$ showed natural, anti-anxiety responses to benzodiazepine, although no sedative effects were observed [5].

Herbal medicines that are used for treatment of anxiety or depression are also related to the function of $\mathrm{GABA}_{\mathrm{A}}$ receptors. Citrus aurantium L. essential oil is one of the most popular local plants in Iran whose flowers in Iranian traditional medicine are prescribed for treatment of mental illnesses such as hysteria and neurasthenia. It is also used as sleep aid, sedative, appetizer, and for eliminating heart palpitation [1]. Various studies show the effectiveness of Citrus aurantium L. in treatment of anxiety, depression, obesity, cancer, as well as its anti-oxidant and anti-inflammatory effects [6]-[8].

Along the same line with past studies, we will further investigate the effect of Citrus aurantium L. essential oil on anxiety and its interaction with GABAergic pathways.

\section{Method and Materials}

This study was done on 84 male albino mice weighed 22 to $28 \mathrm{~g}$ supplied by Pasteur Institute. The mice were assigned to 14 groups of 6 for the experiment. The animals were kept in temperature of $22^{\circ} \mathrm{C}$ to $24^{\circ} \mathrm{C}$ with a 12/12 hour light-dark cycle. Except for the actual percent time of the experiment, the mice had complete access to sufficient food and water. The study started after an acclimation period of 1 week. The terms and conditions of keeping laboratory animals were followed completely during the experiment. All experiments were performed according to the current animal care law of Medical Sciences Research Center, Islamic Azad University, Tehran, Iran.

\subsection{Preparation of the Essential Oil and Drugs}

Collected Citrus aurantium L. flowers were dried and then grinded by an electric mill. $300 \mathrm{~g}$ of the dried powder 
of Citrus aurantium L. were put in a $1000 \mathrm{cc}$ balloon and distilled water was added to make up the volume to 1000 сc. Next, the balloon was put on the heater and connected to the Clevenger apparatus for 2 hours. 2 drops of n-hexane was added to the tube. Essential oil, which was yellow in color and had a strong odor, was then collected and dewatered using sodium sulfate. Then, it was put in open vials and due to exposure to the air the $\mathrm{n}$-hexane vaporized. The vials were completely covered by aluminum foil and kept in a cool place. The essential oil using olive oil was obtained at different densities of $0.5,2.5$, and 5 percent.

Diazepam $(0.1 \mathrm{mg} / \mathrm{kg})$ was supplied by Kimiadarou Company. Diazepman was injected using sodium chloride $9 \%$ (normal saline) sterile.

\subsection{Treatments}

After an acclimation period of 1 week, the animals were injected intraperitoneally with the Citrus aurantium L. essential oil at a certain hour for 5 days. On the fifth day and thirty minutes before applying Citrus aurantium L. essential oil, diazepam $(0.1 \mathrm{mg} / \mathrm{kg})$ was injected to the experimental groups. Thirty minutes after the injection of diazepam, all the groups were assessed for anxiety-related behavior by elevated plus-maze (EPM) test.

\subsection{EPM Test}

The studies were carried out on mice according to the method of Lister [7]. The plus-maze apparatus was made of Plexiglas and consisted of two open $(30 \times 5 \mathrm{~cm})$ and two closed $(30 \times 5 \times 15 \mathrm{~cm})$ arms. The arms extended from a central platform of $5 \times 5 \mathrm{~cm}$. The apparatus was mounted on a Plexiglas base raising it $38.5 \mathrm{~cm}$ above the floor. The test consisted in placing a mouse in the center of the apparatus (facing a closed arm) and allowing it to freely explore. All experiments recorded using personal camcorder. The number of entries into the open arms and the percent time spent in these arms were scored for a 5-min test period. An entry was defined as placing all four paws within the boundaries of the arm. The following measures were obtained from the test: the total number of arm entries; the percentage of arm entries into the open arms; the percent time spent in the open arms expressed as a percentage of the percent time spent in both the open and closed arms. Anxiolytic activity was indicated by increases in percent time spent in open arms or in number of open arm entries. Total number of entries into either type of arm was used as a measure of overall motor activity.

\subsection{Statistical Analysis}

All values were expressed as mean \pm SEM from six animals. The results were subjected to statistical analysis using Unpaired-t test to calculate the significance difference if any among the groups. $P<0.05$ was considered significant (Origin IV).

\section{Results}

Figure 1 shows how the interaperitoneal injection of the essential oil of Citrusaur antium L. (at doses of 0.5, 2.5, and 5 percent) resulted in the increase of the percent time spent in the open arms. In terms of the percent time spent in the open arms, there was a significant difference between the groups that were injected with doses of 2.5 and 5 percent and the control groups $(P<0.001)$.

Figure 2 demonstrates that the interaperitoneal injection of diazepam $(0.1 \mathrm{mg} / \mathrm{kg})$ either alone or with the essential oil of Citrus aurantium L. at dose of 5 percent results in the increase of percent time spent in open arms, which shows a significant difference from control groups $(P<0.001)$. Injection of diazepam and citrusaurantium L. essential oil (at doses of 0.5 and $2 / 5$ percent) together increases the percent time spent in the open arms significantly $(P<0.01)$.

Figure 3 shows how the interaperitoneal injection of the essential oil of citrusaur antium L. (at doses of 0.5, 2.5 , and 5 percent) affected the percent of number of entries in the open arms. There was no significant difference between the groups that were injected with all doses of essential oil and the control groups. However, in higher doses, it tends to increase.

As demonstrated in Figure 4, the interaperitoneal injection of diazepam $(0.1 \mathrm{mg} / \mathrm{kg})$ is also effective in increasing the number of entries to the open arms, which shows a significant difference from control groups $(P<$ 0.001). Applying diazepam and essential oil of Citrus aurantium L. (at doses of 0.5, 2.5 and 5 percent) together leads to the increase of number of entries to the open arms $(P<0.001)$. 


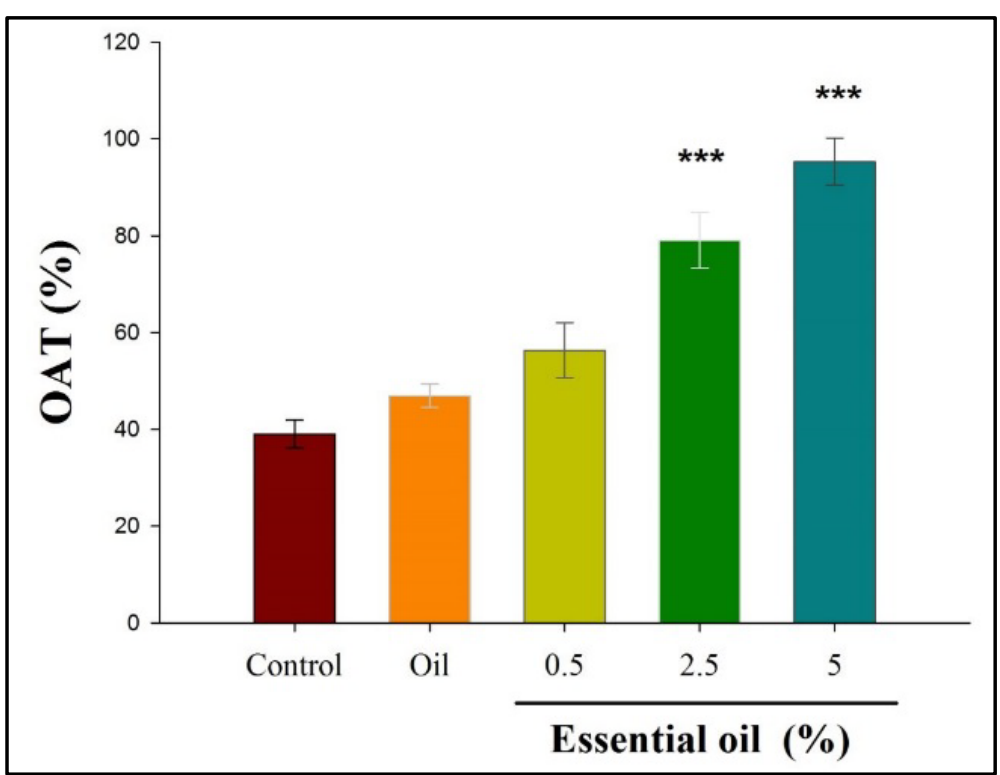

Figure 1. Effect of Citrus aurantium L. essential oil in experimental groups (received essential oil of Citrus aurantium L. at doses of 0.5, 2.5, and 5 percent), control and sham group (received olive oil) on the percent time spend in open arms. Mean \pm S.E.M. $\mathrm{n}=6$. ${ }^{* * * *} \mathrm{P}<0.001$ versus control and sham groups. OAT\% is the percent time spent in open arms.

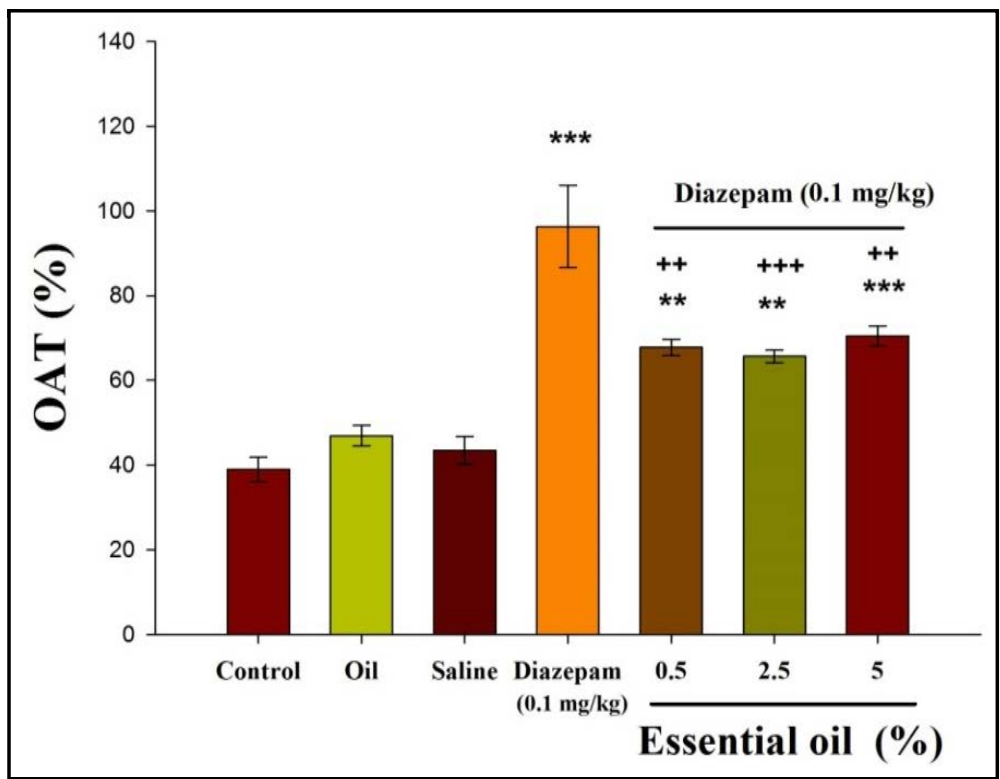

Figure 2. Effect of Citrus aurantium L. essential oil in experimental groups (received essential oil of Citrus aurantium L. at doses of 0.5, 2.5, and 5 percent), control and sham group (received olive oil), Diazepam and its combination with essential oils on the percent time spend in open arms. Mean \pm S.E.M. $n=6 .{ }^{* * *} P<0.001$ versus control and sham groups. OAT\% is the percent time spent in open arms.

\section{Discussion}

The results of this study show that essential oil of Citrus aurantium L., in terms of applied dose, can reduce the anxiety in mice significantly. Sedative and anti-anxiety effects of this plant have been mentioned by past studies. It is possible that these effects are the result of an interaction with GABAergic pathways and subsequent impacts 


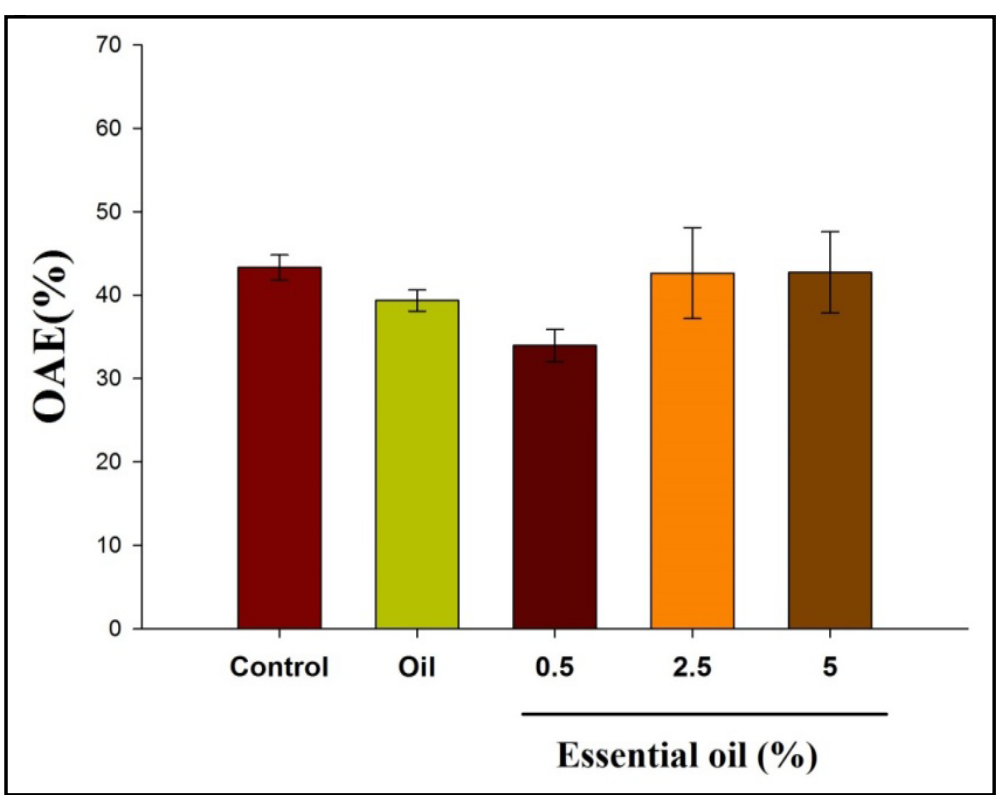

Figure 3. Effect of Citrus aurantium L. essential oil in experimental groups (received essential oil of Citrus aurantium L. at doses of 0.5, 2.5, and 5 percent), control and sham group (received olive oil) on the percent of number of entries in open arms. Mean \pm S.E.M. $n=6$. OAE $\%$ is the number of entries in open arms.

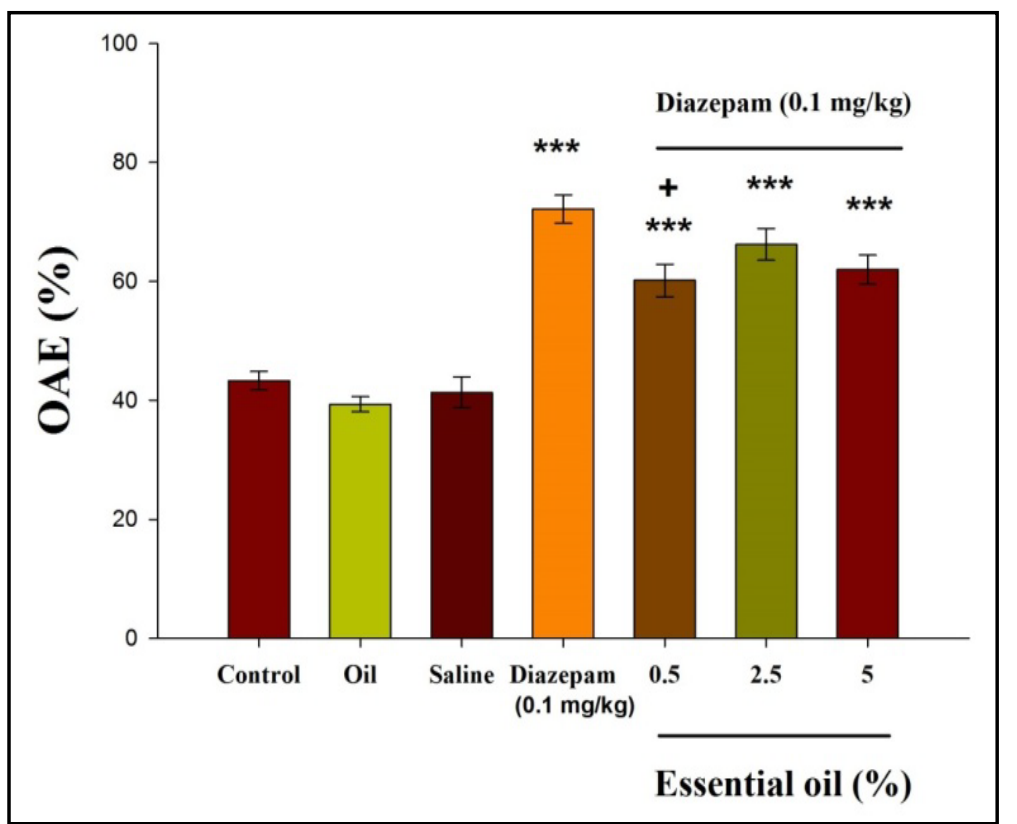

Figure 4. Effect of Citrus aurantium L. essential oil in experimental groups (received essential oil of Citrus aurantium L. at doses of 0.5, 2.5, and 5 percent), control and sham group (received olive oil), diazepam and its combination with essential oils on the percent of number of entries in open arms. Mean \pm S.E.M. $n=6$. Mean \pm S.E.M. $n=6 .{ }^{* * *} P<0.001$ versus control and sham groups. ${ }^{+} P<0.05$ versus diazepam group. OAE\% is the number of entries in open arms.

on $\mathrm{GABA}_{\mathrm{A}}$ receptors. One of the essential compounds of Citrus aurantium L. is limonene which reduces the activity of neurons in central nervous system. After reaching the brain, limonene attaches itself to $\mathrm{GABA}_{\mathrm{A}}$ receptors and reduces anxiety-related activities [9]. Another study shows how limonene, by acting on $\mathrm{GABA}_{\mathrm{A}}$ recep- 
tors, increases the density of gamma-aminobutyric acid and reduces stress [10]. Limonene is therefore one of the compounds in Citrus aurantium L. which has anti-anxiety effects.

Coumarin is another compound in Citrus aurantium L. which has similar sedative effects. A study done by Pereira (2009) demonstrates how acute administration of coumarin to prefrontal cortex and hippocampus of mice can help preventing seizures by effecting $\mathrm{GABA}_{\mathrm{A}}$ receptors and therefore releasing more gamma-Aminobutyric acid in prefrontal cortex. Linalool is also another compound in Citrus aurantium L. which exert inhibitory effects in the nervous system through pre-synaptic inhibition and prevention of acetylcholine release [11]. Linalool is a competitive antagonist for glutamate receptors; consequently, by blocking these receptors, it reduces the effect of this neurotransmitter system and prevents epileptic and anxiety-related fits [12]. Flavonoids are still another compound in Citrus aurantium L. which, in terms of the mechanism of the effect, suppress the nervous system activity and bring about sedation through their high tendency toward benzodiazepines receptors. Mahmoodi (2005), in his study on rats, shows that flavonoid compounds in Citrus aurantium L. can play a significant part in reducing anxiety in these animals [3]. Flavonoids are often appropriate ligands for $\mathrm{GABA}_{\mathrm{A}}$ receptors and, as a great number of studies show, have benzodiazepine-like features [10] [13]. Some flavonoids are called herbal benzodiazepine because of their similarity with benzodiazepines in terms of effects [14]. As we already observed in the results of this study, administration of the essential oil of Citrus aurantium L. at different doses increases the percent time spent in open arms and the number of the entries to the open arms, which is a manifestation of anti-anxiety effect of this essential oil. This effect can be due to the effects of the different compounds mentioned in previous studies which reinforce the GABAergic system in the brain and which by increasing the release of GABA and reducing the activity of the central nervous system, produce calming effect in mice.

Shabanian (2008), by studying the effect of the essential oil of Citrus aurantium L. and diazepam before surgical operations, concludes that both Citrus aurantium L. and diazepam are effective drugs for reducing the level of anxiety in patients before surgeries [15].

In the current study, we illustrated that diazepam $(0.1 \mathrm{mg} / \mathrm{kg})$ either alone or with different doses of Citrus aurantium L. essential oil significantly increases the percent time spent in the open arms and the number of entries to the open arms. The result of this study confirms past studies on the anti-anxiety effect of diazepam and citrusaurantium L. essential oil.

\section{Acknowledgements}

We would like to thank Dr. Hedayat Sahrai for his valuable help and guide.

\section{References}

[1] Andreasen, N.C. (2004) Acute and Delayed Posttraumatic Stress Disorder: A History and Some Issues. American Journal of Psychiatry, 161, 1321-1323. http://dx.doi.org/10.1176/appi.ajp.161.8.1321

[2] Arrindell, W.A., Eisemann, M., Richter, J., et al. (2003) Phobic Anxiety in 11 Nations. Part1: Dimensional Constancy of the Five-Factor Model. Behaviour Research and Therapy, 41, 469-479.

[3] Cohen, S.M.D. (1983) The Anxiolytic Agents. Drug Abuse and Alcoholism. Newsletter, 12, 1-4.

[4] Mandrioli, R., Mercolini, L. and Raggi, M.A. (2008) Benzodiazepine Metabolism: An Analytical Perspective. Current Drug Metabolism, 9, 827-844. http://dx.doi.org/10.2174/138920008786049258

[5] McKernan, R.M., Rosahl, T.W., Reynolds, D.S., Sur, C., Wafford, K.A., Atack, J.R., et al. (2000) Sedative But Not Anxiolytic Properties of Benzodiazepines Are Mediated by the GABAA Receptor Alpha (1) Subtype. Nature Neuroscience, 3, 587-592. http://dx.doi.org/10.1038/75761

[6] Amravati, J. and Suryawanshi, S. (2011) An Overview of Citrus aurantium Used in Treatment of Various Diseases. African Journal of Plant Science, 5, 390-395.

[7] Carvalho-Freitas, M.I. and Costa, M. (2002) Anxiolytic and Sedative Effects of Extracts and Essential Oil from Citrus aurantium L. Biological and Pharmaceutical Bulletin, 25, 1629-1633.

[8] Colker, C.M., Kalman, D.S., Torina, G.C., Perlis, T. and Street, C. (1999) Effects of Citrusaurantium Extract, Caffeine, and St. John's Wort on Body Fat Loss, Lipid Levels, and Moodstates in Overweight Healthy Adults. Current Therapeutic Research, 60, 145-153. http://dx.doi.org/10.1016/S0011-393X(00)88523-9

[9] Re, L., Barocci, S., Sonnino, S., et al. (2000) Linalool Modifies the Nicotinic Receptor-Ionchannel Kinetics at the Mouse Neuromuscular Junction. Pharmacological Research, 42, 177-181. http://dx.doi.org/10.1006/phrs.2000.0671 
[10] Silva Brum, L.F., Emanuelli, T., Souza, D.O., et al. (2001) Effects of Linalool on Glutamaterelease and Uptake in Mouse Cortical Synaptosomes. Neurochemical Research, 26, 191-194. http://dx.doi.org/10.1023/A:1010904214482

[11] Deckers, C.L.P., Genton, P., Sills, G.J. and Schmidt, D. (3003) Current limitations of Antiepileptic Drug Therapy: A Conference Review. Epilepsy Research, 53, 1-17. http://dx.doi.org/10.1016/S0920-1211(02)00257-7

[12] Johnston, G.A.R. (2005) GABA A Receptor Channel Pharmacology. Current Pharmaceutical Design, 11, $1867-1885$. http://dx.doi.org/10.2174/1381612054021024

[13] Marder, M., Estiú, G., Bruno Blanch, L., et al. (2001) Molecular Modeling and QSAR Analysis of the Interaction of Flavone Derivatives with the Benzodiazepine Binding Site of the GABAA Receptor Complex. Bioorganic \& Medicinal Chemistry, 9, 323-335. http://dx.doi.org/10.1016/S0968-0896(00)00250-9

[14] Shen, D.W., Higgs, M.H., Salvay, D., Olney, J.W., Lukasiewicz, P.D. and Romano, C. (2002) Morphological and Electrophysiological Evidence for an Ionotropic GABA Receptor of Novel Pharmacology. Journal of Neurophysiology, 87, 250-256.

[15] Shabanian, Gh., Pourya, M.E. and Akhlaghi, M. (1387) The Effect of Citrus aurantium and Diazepam on Reducing Anxiety before Surgery. Journal of Shahrekord University of Medical Sciences, 4, 13-18. 
Scientific Research Publishing (SCIRP) is one of the largest Open Access journal publishers. It is currently publishing more than 200 open access, online, peer-reviewed journals covering a wide range of academic disciplines. SCIRP serves the worldwide academic communities and contributes to the progress and application of science with its publication.

Other selected journals from SCIRP are listed as below. Submit your manuscript to us via either submit@scirp.org or Online Submission Portal.
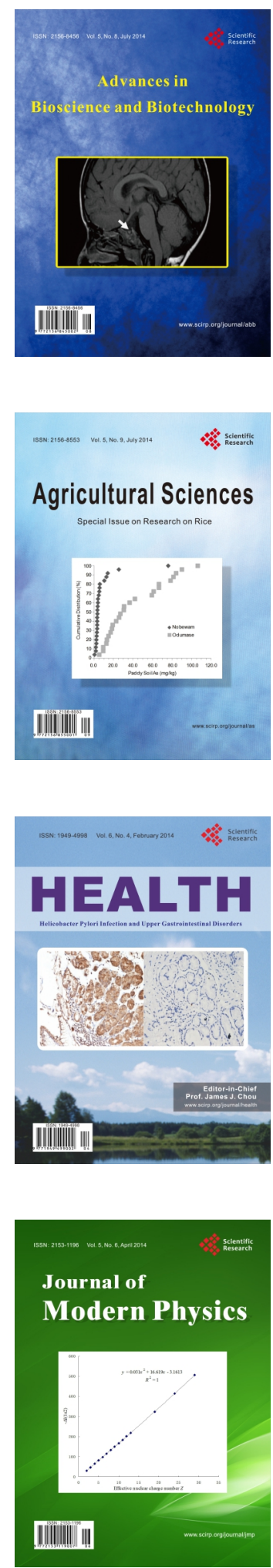
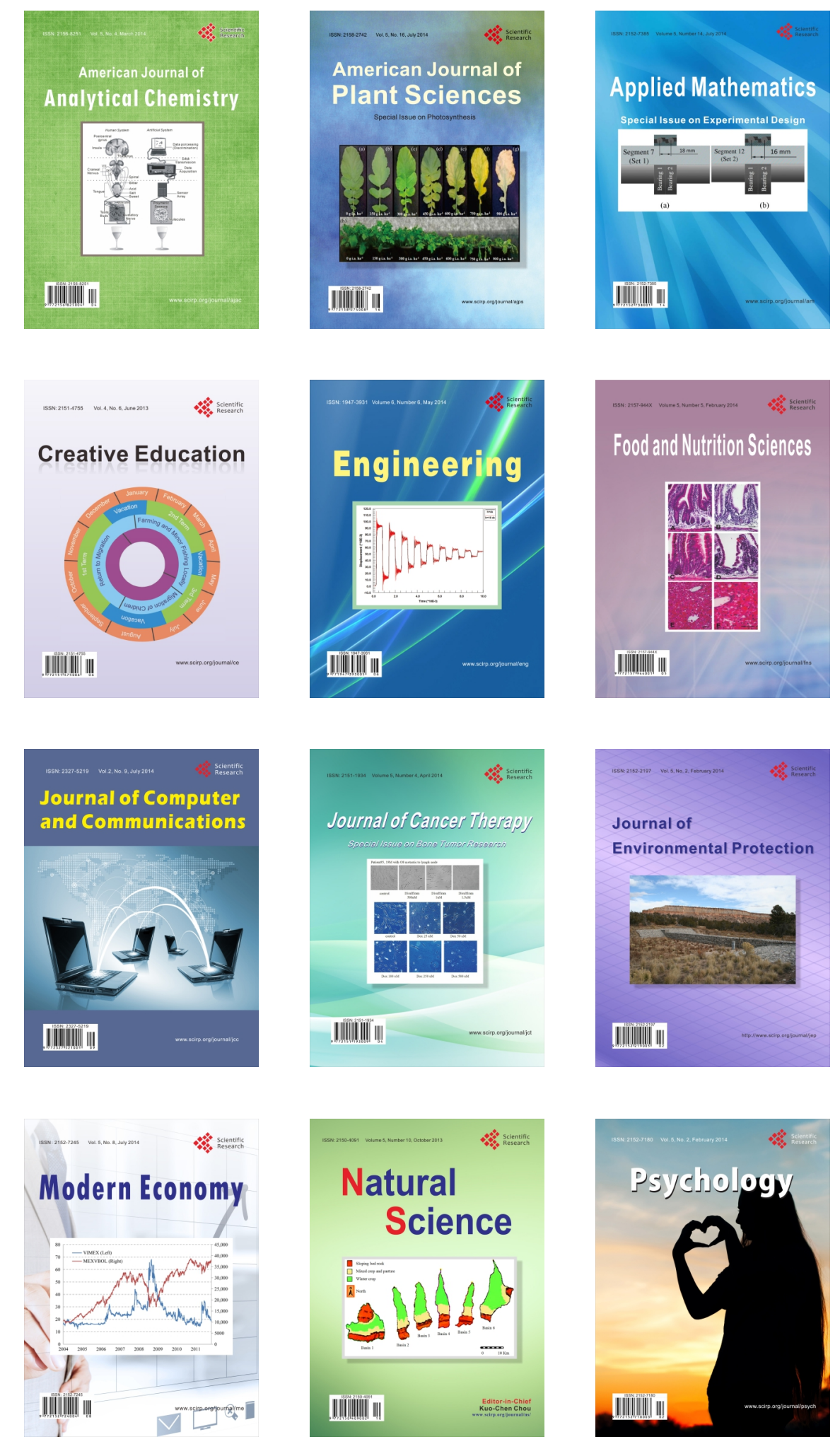